\title{
Pañuelazos por el aborto legal, seguro y gratuito
}

\section{Estética y política: análisis del activismo feminista en la Argentina durante 2018}

\author{
Pañuelazos for Safe and Free Legal Abortion \\ Aesthetics and Politics: Analysis of Feminist Activism in Argentina during 2018
}

\section{Clara Presman \\ presmanclara@gmail.com \\ https://orcid.org/0000-0001-5727-4633}

Centro de Investigaciones de la Facultad de Filosofía y Humanidades

Universidad Nacional de Córdoba | Argentina

\section{Resumen}

En el presente artículo la autora indaga sobre los cruces entre estética y política, sus conjunciones y sus desvíos como territorios fértiles desde donde pensar la cultura y las sociedades contemporáneas. A partir de afirmar que las políticas visuales de los movimientos sociales se han apropiado de la calle con gran fuerza, se abordan las intervenciones artísticas que devinieron de los llamados pañuelazos, durante la coyuntura política de 2018 en la Argentina, en el marco de la lucha por la legalización y la despenalización del aborto.

Palabras clave | pañuelazos, aborto, activismo artístico, espacio público

\section{Abstract}

In this article the authoress investigates the crossings between aesthetics and politics, their conjunctions and deviations as fertile territories from which to think about contemporary culture and societies. Asuming that the visual policies of social movements have appropriated of the streets with great force, the artistic interventions that became the so-called «pañuelazos» are addressed, during the political situation of 2018 in Argentina, in the fight for the legalization and decriminalization of abortion.

Keywords | pañuelazos, abortion, artistic activism, public space 


\title{
Pañuelazos por el aborto legal, seguro y gratuito
}

\author{
Estética y política: análisis del activismo \\ feminista en la Argentina durante 2018
}

Por Clara Presman

Si se pretende hacer un arte revolucionario en términos políticos primero tiene que serlo en términos artísticos.

Mónica Mayer (2007)

Los cruces entre estética y política, sus conjunciones y sus desvíos resultan territorios fértiles desde donde pensar la cultura y las sociedades contemporáneas. Las políticas visuales de los movimientos sociales organizados en torno a diversas luchas y reivindicaciones se han apropiado de la calle con gran fuerza. En la actualidad, las intervenciones artísticas que despliegan los movimientos sociales que irrumpen en el espacio público para visibilizar sus demandas resultan centrales para disputar sentidos en diversos conflictos sociopolíticos.

En los últimos años, el movimiento feminista ha conquistado la escena pública latinoamericana con gran fuerza y es indudable que la agenda feminista está instalada en la región de manera consolidada y ha tomado cada vez mayor preponderancia. En la historia de la Argentina, el movimiento de mujeres ha sido significativamente vanguardista, también ha sido reprimido y censurado, aunque siempre logró recomponerse y resignificarse. En este marco, durante 2018, la discusión por el Proyecto de Ley de Interrupción Voluntaria del Embarazo (IVE) ${ }^{1}$ fue un debate que no solo se dio en el recinto de diputados y de senadores sino, y sobre todo, en las calles. 
En el presente artículo se abordan las intervenciones artísticas que devinieron de los llamados pañuelazos, durante la coyuntura política de 2018, un momento con características fuertemente emancipadoras para las mujeres argentinas, quienes impulsaron la lucha por el derecho de las mujeres y las identidades feminizadas de decidir libremente sobre la maternidad y sobre sus cuerpos, disputando la apropiación del espacio público como un escenario más desde donde protagonizar la lucha. A pesar de un contexto nacional poco favorable, con un gobierno que desplegó un dispositivo represivo absolutamente presente en la calle, esta disputa en el espacio público se tornó estratégica para analizar el proceso de discusión por la aprobación de la ley.

Durante 2018, el escenario urbano público fue fuertemente habitado por el movimiento feminista en apoyo a la Campaña Nacional por el Derecho al Aborto Legal, Seguro y Gratuito y, sin dudas, las intervenciones artísticas fueron las grandes protagonistas de esta perseverante lucha. El activismo estético, con diversas intervenciones de las más variadas expresiones artísticas, representó las demandas y las percepciones en torno al conflicto y la lucha de las mujeres por la soberanía de sus cuerpos y de sus decisiones. Es preciso señalar que tales expresiones artístico culturales fueron llevadas a cabo por artistas y por activistas en defensa de la Campaña Nacional por el Derecho al Aborto Legal, Seguro y Gratuito, pero también, aunque en mucho menor medida, por aquellas mujeres que expresan su repudio al proyecto de ley bajo el lema «salvemos las dos vidas».

Atento a estas consideraciones, en el presente ensayo se propone realizar un breve recorrido por el arte activista en la Argentina, desde sus comienzos hasta la actualidad, para luego problematizar el vínculo entre arte, política y espacio público.

Cuando nos referimos a la cultura, en este caso, lo hacemos retomando a Néstor García Canclini, quien apunta la importancia de re-definir el concepto de cultura, lo que permite su ubicación en el campo político. De este modo, se concibe a la cultura, ya no solamente como aquello meramente relacionado a la alta literatura y a las bellas artes, sino, desde un sentido más próximo al concepto antropológico, como el conjunto de procesos mediante los cuales se elabora la significación de las estructuras sociales, se las representa y se las transforma a través de operaciones simbólicas (García Canclini \& Cruces, 2012). Si bien la cultura hegemónica legitimada en los espacios consagrados de circulación, de recepción y de crítica es la 
que condiciona el posicionamiento de las demás expresiones, tal como como explica Pierre Bourdieu (2010), «la cultura media está objetivamente definida por el hecho de estar condenada a definirse en relación con la cultura legítima, tanto en el dominio de la producción como en el dominio de la recepción» (p. 119).

Sobre este tópico, Reinaldo Laddaga (2006), al preguntarse ¿qué es una cultura?, explica:

Es un conjunto de ideas, sí, más o menos articuladas, un patchwork más o menos bien tejido, pero también un repertorio de acciones con que se encuentra el participante de una escena a la hora de actuar, repertorio que se vincula a un conjunto de formas materiales y de instituciones que facilitan la exhibición y la circulación de cierta clase de productos y que favorece un cierto tipo de encuentro con los sujetos a los que están destinadas. Una cultura, en este sentido, es un poco lo que el filósofo francés Jacques Ranciere llama un «régimen de las artes». ¿Qué es un régimen de las artes para Ranciere?, un tipo específico de vínculo entre modos de producción de obras o prácticas, formas de visibilidad de estas prácticas y modos de conceptualización de unas y otras. No sólo eso: un régimen es un vínculo entre modos de producción, formas de visibilidad y modos de conceptualización que se articula con las formas de actividad, de organización y de saber que tienen lugar en un universo histórico determinado: "Las prácticas artísticas son "maneras de hacer" que intervienen en la distribución general de las maneras de hacer y en sus relaciones con las maneras de ser y las formas de visibilidad» (p. 22).

Desde este modo de entender el arte y la cultura se analizarán en este trabajo los cruces entre el arte, la política y los movimientos feministas que tienen en la Argentina una larga trayectoria de diálogos y de disputas. Desde la potente porosidad de los territorios del arte, en los cruces y en las hibridaciones de lenguajes, de modos de construcción de discursos. Como define Laddaga (2006), en relación con el desbordamiento y los efectos de la globalización sobre el arte tradicional, y el surgimiento y la proliferación de nuevos proyectos: 
Proyectos irreconocibles desde la perspectiva de las disciplinas, ni producciones de "arte visual» ni de «música», ni de "literatura» que, sin embargo, se encuentran inequívocamente en su descendencia; producciones de las cuales es difícil decidir a qué tradición nacional o continental pertenecen -si se trata de arte argentino, americano o francés- y donde, sin embargo, se interroga la relación entre la producción de representaciones y de imágenes, y las formas de la ciudadanía (p. 12).

Ana Longoni (2010b) aborda los cruces entre arte y política en la Argentina corriéndose de la idea más convencional de arte político. La autora argumenta que no asume lo político como un adjetivo del arte, en el sentido de un rasgo que caracteriza a cierto tipo de arte en el cual habitualmente la cuestión artística aparece subordinada, o casi como un aspecto decorativo, respecto de ciertos programas de intervención política. Su propuesta consiste en pensar los vínculos entre el arte y la política como necesariamente conflictivos, complejos, de fuertes tensiones, y asemeja esta relación a la idea de desbordamientos, es decir,

[a] las contaminaciones, las intersecciones, las mutuas redefiniciones que entre el arte y la política se producen en momentos históricos cruciales, que no se dan continuamente sino en ciertas coyunturas, en ciertos momentos. Habitualmente, tienen que ver con momentos de gran conmoción social o con procesos políticos de fuerte signo emancipador, por decirlo en términos genéricos, donde esas articulaciones superan esta suerte de esferas autónomas en las que la modernidad viene comprendiendo al arte y la política y permite reformulaciones mutuas que dejan re-situado y redefinido tanto al arte como a la política (Longoni, 2010b, p. 2).

\section{Cruces entre arte y política: breve recorrido histórico}

En la Argentina, el largo camino de articulación entre producción artística y acción política que se remonta, al menos, a fines del siglo XIX, es recorrido por Longoni (2010b), quien explica que este vínculo constituye «un territorio de tensiones, de desencuentros y de proposiciones utópicas, polémicas públicas y adhesiones 
secretas» (p. 1). Si bien existen diferentes modos de llamar a estos cruces, acuñados por diferentes teóricos/as, tales como «artivismo», «arte político» o «arte militante» entre otros, en el presente ensayo se recurre al concepto que utiliza Longoni (2010b) de "activismo artístico», el cual es retomado de la autodefinición propuesta por el dadaísmo alemán. Bajo esta definición, la autora agrupa «las producciones y las acciones, muchas veces colectivas, que abrevan en recursos artísticos con la voluntad de tomar posición y de incidir de alguna forma en el territorio de lo político» (Longoni, 2010b, p.1).

En su historizacion sobre la última década, Longoni (2010b) sitúa dos coyunturas cruciales en la aparición y la multiplicación de grupos de activismo artístico. La primera la ubica en el surgimiento de H.I.J.O.s (Hijos por la Identidad y la Justicia contra el Olvido y el Silencio), agrupación nacida en 1996 que reúne a hijos/as de detenidos/as-desaparecidos/as durante la última Dictadura cívico militar ocurrida entre 1976 y 1983; la segunda, en el período comprendido entre diciembre de 2001 y la asunción del presidente Néstor Carlos Kirchner, a mediados de 2003. En esta etapa de gran efervescencia política, el clima nacional se vio marcado por una fuerte inestabilidad institucional y por una continua agitación callejera, así como por la emergencia de colectivos organizados que se conocieron como «nuevos protagonismos sociales», y cuyas lógicas de acción fueron las asambleas populares, los piquetes o cortes de ruta, protagonizados por trabajadores de fábricas recuperadas, por movimientos de desocupados, etcétera.

Coincidente con aquella primera coyuntura histórica, a partir de la década del setenta también irrumpen en la escena artística local, desde el pensamiento de la segunda ola feminista, las artistas mujeres, evidenciando las restricciones discursivas, formativas y teóricas imperantes en la institución Arte. De este modo, denuncian a la historia del arte, al discurso del arte y a la institución Arte de ser un orden arbitrario investido, casi en su totalidad, por el deseo masculino. Como en casi todos los ámbitos históricamente habitados y liderados por hombres, la presencia de mujeres incomoda. Molesta. El arte es también una esfera que ha sido difícil de apropiar por parte de las mujeres, y en la cual como modo de deslegitimar y de menospreciar los aportes de artistas mujeres muchas veces se ha negado el trasfondo profundamente crítico que dicho proyecto plantea y que planteó desde sus comienzos. Así, a menudo se analiza el arte feminista como un estilo dentro del arte y se pretende, incluso, hablar de arte feminista en referencia a un arte femenino, equiparando femenino a feminista (Menoyo, 2011). 
En este sentido, y en línea con lo propuesto por Sofía Menoyo (2011) y por Ana Longoni (2010a), afirmo mi certeza de entender al arte feminista como un proyecto político, lo cual, en palabras de esta última, no niega su condición poética sino que la amplia más allá de los límites modernos del arte. Y de entender, además, que el arte feminista no es solo un proyecto político dentro del arte -es decir, un proyecto político que utiliza el arte como herramienta- sino que es, a su vez, un proyecto artístico.

Desde estos paradigmas, intentaremos dar cuenta de las particularidades devenidas de la conjunción entre la formación artística y la práctica como militantes y como activistas feministas en las calles a partir de las intervenciones artísticas motivadas por los llamados pañuelazos, a fin de acreditar, a partir de dichas intervenciones, las modalidades que adquirieron las manifestaciones artísticas en el espacio público.

\section{La marea verde}

Una marea verde de pañuelos se hizo presente en las diferentes ciudades argentinas. Las mujeres se volcaron a las calles con gran fuerza en defensa de sus derechos. Pero esta manifestación organizada de mujeres que ocupan el espacio público no es novedad en el país, sino que tiene una larga trayectoria. Primero, los pañuelos blancos de las Madres y las Abuelas de Plaza de Mayo; luego, y con interesantes puntos de confluencia y de continuidad, irrumpieron en el espacio público los pañuelos verdes. La marea verde no se constituyó como tal de manera mágica ni azarosa sino que fue la expresión contundente y visibilizada a través de la insignia del pañuelo verde portador de múltiples significaciones del trabajo acumulado de muchos años de lucha y de organización del movimiento de mujeres de la Argentina.

En este sentido, es fundamental analizar la capacidad y la potencialidad que percibe un movimiento emancipatorio en un momento histórico determinado para constituirse como acontecimiento. Sobre esto, interesa reflexionar sobre las estrategias creativas y las configuraciones estéticas singulares aportadas por los movimientos feministas situados en torno a los diversos reclamos contingentes e históricos de las mujeres. 
La convocatoria a los pañuelazos se realizó vía redes sociales: Facebook, Twitter, Instagram y WhatsApp fueron las principales plataformas utilizadas. Estas no solo sirvieron para crear eventos y para brindar la información tendiente a lograr la masividad alcanzada, sino que, a decir de la periodista e investigadora Julieta de Titto (2018), habilitaron la construcción y la circulación de nuevas narrativas. Hecho doblemente celebrable: por un lado, por el valor de que las mujeres tomen la palabra, quebrando años de silencio en los que la escritura, el periodismo y los espacios de visibilidad pública eran privilegio de varones; por el otro, por hacer frente a la brecha digital de género que existe en el acceso a las tecnologías. ${ }^{2}$ Así, las redes sociales en la protesta social por la aprobación de la ley de IVE se conformaron como plataformas que habilitaron la organización y el debate.

Todos los pañuelos juntos, levantados en un mismo grito y en movimiento, con la masividad que tuvieron las convocatorias, se transformaron en una «marea feminista». Judit Butler (2019) reflexionó sobre el sentido construido en torno a la noción de "marea» y explicó que esta supera en algún sentido a la periodización del feminismo occidental europeo y norteamericano que divide las etapas del feminismo en olas. Las olas del feminismo, explicó la filósofa, se centran en relatar una parte de la historia del movimiento feminista de manera geo situada y lineal, lo que deja por fuera muchas otras expresiones de los feminismos a nivel global como los latinoamericanos, los descoloniales o los comunitarios. La marea, en cambio, va y viene, es dinámica. Avanza y retrocede hacia un futuro desconocido e impredecible, pero siempre en continuo movimiento. Como apuntó Butler (2019), el futuro de la marea es incierto pero la certeza es la organización, la potencia y las convicciones que crecen con el tiempo. Garantía de que hay un horizonte de lucha feminista al final del camino y que la marea puede retroceder y avanzar, pero nunca dejar de moverse.

Además del encuentro para elevar los pañuelos frente al Congreso de la Nación en la Ciudad Autónoma de Buenos Aires, los pañuelazos comenzaron a replicarse en otras localidades del país e instalaron un modo de apropiarse de la trama de la ciudad, haciendo las veces de puntapié para habilitar otros modos de ocupar el espacio público, siempre con los pañuelos como bandera de lucha, como símbolo inconfundible que irrumpió con rebeldía en la escena cotidiana de casi todos los puntos geográficos de la Argentina. 
Durante los meses que duró el debate en la Cámara de Diputados hubo diferentes actividades que terminaron con un pañuelazo. Los llamados «martes verdes» fueron festivales de mujeres con diferentes expresiones artísticas: poesía, música, baile, en tono feminista, y con un solo tema: Aborto Legal Ya.

El factor intergeneracional emerge como un común denominador de este modo de la protesta, al igual que en la identidad propia de la Campaña. Como nunca antes en la trayectoria de las mujeres en el país, se configuró un modo de ocupar el espacio público de manera conjunta entre mujeres de diversas generaciones, constituyéndose, así, un enlace entre el cuerpo propio y el cuerpo mancomunado en un mismo reclamo. En la calle, las jóvenes sostenían el reclamo para que dentro del recinto no olvidaran que los cuerpos de miles de mujeres estaban ahí, esperando por sus derechos; dentro del recinto, las mujeres que históricamente lucharon por la legalización y la despenalización del aborto, junto con profesionales y con diputadas, presionaban en el plano parlamentario. En efecto, por primera vez en la historia de las luchas del feminismo en la Argentina, de manera ubicua, se articuló una demanda urgente, como es el derecho a la vida sexual desvinculada de la inexorabilidad reproductiva, en un inédito y potente diálogo entre generaciones (Elizalde, 2018).

La sinergia entre grupos de diferentes franjas etarias se vio fuertemente reflejada en los modos de acción de los pañuelazos. Como explica Federico Schuster (2005), en las acciones estratégicas que se desarrollan en la protesta social se ponen en juego, por un lado, una dialéctica de lo viejo y lo nuevo, entre las tradiciones históricas de lucha y los nuevos modos que imprimen las jóvenes; por el otro, las expresiones creativas con rasgos propios de la generación que conforma el sujeto de la protesta. Es por esto que al profundizar sobre el formato en que la protesta aparece en la escena pública surgen rasgos tales como la identidad, las tradiciones culturales y las marcas del contexto.

En línea con este planteo, los pañuelazos estuvieron fuertemente atravesados por el signo estético y expresivo de una generación en la cual la tensión y el diálogo entre lo nuevo y lo viejo estuvieron presentes tanto en el discurso como en la forma estética. Así, las jóvenes recuperaron, por un lado, temas «clásicos» del feminismo como el aborto y la autodeterminación de los cuerpos de las mujeres, e incluyeron, por otro, tópicos propios de su experiencia vital generacional, como el acoso sexual y callejero, los micro machismos o la necesidad de incorporar un lenguaje inclusivo 
que nombre y que interpele al colectivo de la diversidad. Los pañuelazos, como modo de ejercicio de ciudadanía en el espacio público, si bien tuvieron como motivo principal la visibilización de la lucha por la ley de IVE, y el objetivo de generar en la sociedad el impacto necesario para que esto influyera en las decisiones jurídicas, también construyeron en el reclamo otros sentidos.

En el diálogo intergeneracional reflejado en este formato particular, como uno de los modos más potentes que tuvo la protesta social, las mujeres mayores, militantes históricas o recién llegadas a la arena de la participación política, proveyeron estrategia, persistencia y sólida argumentación; las más jóvenes, en tanto, también aportaron argumentos contundentes desde sus trayectorias y agregaron su potencia movilizadora y expresiva, caracterizada por la creatividad y la espectacularización. Se tejió, de este modo, una poderosa estrategia de transversalización social de la agenda de género, que dio cuenta de la masividad de una lucha hecha cuerpo. Potenciada por la visibilidad mediática y la rápida difusión aportada por las redes sociales e internet (Elizalde, 2018).

Es por esto que el pañuelo verde se convirtió en un significante que adquiere diversos significados de la lucha feminista, que irrumpe en la cotidianeidad en diferentes espacios. En cuanto a los modos de aparición, los pañuelazos estuvieron marcados por una dimensión espectacularizada de las acciones y las performances públicas. Elizalde (2018) explica que las jóvenes protagonistas fueron llamadas «la generación glitter», ${ }^{3}$ en referencia al maquillaje con brillo utilizado por la mayoría.

En palabras de la autora, las protagonistas de los pañuelazos,

[...] articulan fluida y constantemente sus interacciones cotidianas y de praxis política con una variedad de lenguajes, soportes y mediaciones tecnológicas. En este sentido, su activa participación en la escena política asociada a derechos está marcada tanto por el diálogo y la complicidad intergeneracional con las mayores, como con cierta variabilidad de posicionamientos frente a los feminismos organizados. Esto se advierte, por ejemplo, en el tipo de apropiación que alcanzan de ciertos contenidos y repertorios de acción en el campo concreto de sus tomas de decisión personales y colectivas, sus modos de ejercicio y/o reclamos de derechos, sus vidas de relación y sus interacciones y tránsitos por las instituciones, todo lo cual impide una interpretación totalizadora o conclusiva sobre esta nueva coyuntura relacional, en plena construcción (Elizalde, 2018, p. 90). 
Otro punto central del modo de aparición de la marea verde en el espacio público fueron las mediaciones tecnológicas. Por su impacto visual de gran valía, las imágenes tomadas en estas intervenciones y compartidas en las redes sociales de las protagonistas rápidamente se viralizaron, lo que generó repercusiones a nivel nacional e internacional y permitió construir una serie de discursos que se multiplicaron, deslocalizados del tiempo y del espacio de su aparición. Así, las redes sociales, como en muchas otras protestas sociales contemporáneas, tuvieron un papel decisivo tanto para la convocatoria a los pañuelazos como para su posterior reproducción.

De este modo, se fortalecieron tramas de relaciones, de sensibilidades y de afectos. Redes entre mujeres de diversos sectores y generaciones, hermanadas en una lucha y materializadas en un cuerpo colectivo. Esto constituye, a decir de Elizalde (2018), «marcos de reconocimiento, sororidad y referencia intra-género, y de continuidad y reapropiación intergeneracional que operan como guía y/o incentivo para el presente» (p. 91). Este particular modo de producción y de apropiación del espacio público que, como explicamos, siempre está mediatizado, representó una historia de rebeldía femenina que va tejiendo redes infinitas, con una punta de ovillo sostenida por abuelas incansables y que se continúa desplegando en las más jóvenes con sus cuerpos pintados de brillo y de verde lucha. Emergieron, así, nuevos modos de estar en el espacio y de luchar por derechos fundamentales y contra una opresión patriarcal que opera, también, en el plano jurídico. Con memoria de un acontecer que preexiste y que puede continuarse bajo nuevas formas, que condensa experiencias y que produce nuevas emergencias igual de necesarias y de urgentes.

\section{De pañuelos blancos y verdes}

En la Argentina, los pañuelos tienen una carga emocional histórica. Han simbolizado la lucha de las mujeres desde los años setenta. Los pañuelos blancos, como símbolo de la resistencia de las Madres y las Abuelas de Plaza de Mayo; los pañuelos verdes, en la actualidad, como emblema de la lucha feminista. El pañuelo blanco de las Madres y las Abuelas ha sido utilizado como modo de protesta contra los gobiernos dictatoriales y para el pedido de aparición de miles de desaparecidos y desaparecidas durante la Dictadura cívico eclesiástico militar. 
Sobre la utilización de los pañuelos blancos, Bilbao (2017) explica:

Ese acto performático y político se repite año a año, de manera reiterada. Tiene un contexto político, está situado y tiene una impronta transformadora a nivel social. En la Argentina, y también en el mundo, sabemos qué significa «la ronda de las Madres». En este sentido, es importante comprender que estas acciones artísticas y políticas forman parte de un saber social, de la construcción de la memoria y también de una identidad (p. 8).

De esta misma manera, los pañuelos verdes se han transformado en el símbolo de la lucha feminista en la Argentina, reconocida también a nivel mundial, e irrumpen en diferentes espacios como huella de una disputa, de una batalla de las mujeres por sus derechos y por la soberanía de sus cuerpos. Ya no representan estricta y únicamente a la Campaña Nacional por el Derecho al Aborto Legal Seguro y Gratuito, sino que son el símbolo de la lucha feminista que encarna diversos sentidos, además de la lucha por la legalización y la despenalización del aborto. Como herederas de las Madres y las Abuelas, portadoras de una lucha por derechos humanos, las mujeres argentinas de diferentes generaciones empuñan en alto sus pañuelos verdes.

Como hemos desarrollado, los pañuelos verdes no solo tiñeron las calles de las ciudades argentinas, sino que se convirtieron en un símbolo identitario de las mujeres feministas y, de especial manera, de una generación. Se transformaron en la muestra de la irreverencia hacia el poder eclesiástico y político, en parte del paisaje urbano y de un discurso público. Las jóvenes, las adolescentes y las niñas que se volcaron a la militancia feminista a partir de la discusión por la ley de IVE se apropiaron del pañuelo como un elemento que las identifica y lo llevan como insignia en su cotidianeidad: atado en mochilas, en brazos, en el pelo y en otros lugares visibles, como marca indeleble de una lucha que atravesó una generación. Los pañuelos blancos y los pañuelos verdes, en la actualidad, se acompañan, se comprenden y se entrelazan.

La ocupación del espacio público por parte de la campaña, como hemos analizado, fue sumamente intensa durante las semanas previas a la discusión en la Cámara de Diputados y en la Cámara de Senadores (el 14 de junio y el 8 de agosto, 
respectivamente), durante los días de debate y, también, durante las semanas y los meses posteriores hasta la actualidad. Si bien el Senado rechazó el proyecto en agosto de 2018, se buscó reimpulsar la iniciativa en la calle. A través de un comunicado replicado en las redes sociales, desde la Campaña -tomando como puntapié la iniciativa de los pañuelazos, en tanto propuesta que de alguna manera surgió de esta última- se convocó a toda la sociedad a sumarse al activismo en las redes y en las calles, y a participar de las actividades organizadas en cada ciudad. En este marco, y bajo la consigna de no abandonar las calles pese al resultado en la Cámara de Senadores, cada semana se convocó a pañuelazos de menor masividad, no solo en diferentes ciudades de la Argentina sino en numerosos países, desde Brasil y Bolivia hasta Australia y Dinamarca, pasando por España e Italia.

Una vez más, las calles se tiñeron de verde aborto. De verde lucha. Desde la Campaña se invitó a intervenir los espacios públicos de diferentes maneras impregnando el ambiente de verde. Tal como explica Longoni (2010b), el arte político se vale del aprovechamiento subversivo de circuitos masivos como la publicidad callejera, los afiches, la gráfica urbana y la generación de dispositivos de comunicación alternativa como nuevas modalidades de protesta.

Concretamente, la convocatoria fue a intervenir el espacio público como ejercicio de ciudadanía, a través de expresiones artísticas diversas. Fue un llamado a todas las mujeres, en primer lugar, y en segundo a lugar a los hombres que se sintieran interpelados por la demanda. No fue una invitación únicamente a artistas, cualquier persona que quisiera podía intervenir el espacio con su pañuelo y con los elementos que deseara, y en los lenguajes que considerase más adecuados. Pancartas, carteles, grafitis, performances, danza, música, poesía. Todo relato era válido para aportar a al visibilización de la lucha.

La mediatización, una vez más, tuvo un rol protagónico. La presencia en la cobertura tanto de los medios de comunicación tradicionales como en las redes sociales fue central en la estrategia de los pañuelazos y en las intervenciones que los acompañaron. Es decir, se trató de una idea creativa, puesta a disposición de un dispositivo de comunicación de masas.

Esta situación puede asemejarse a expresiones artísticas surgidas luego de la última Dictadura cívico militar eclesiástica. Longoni (2010b) sostiene que los años setenta constituyeron un período bisagra, dado que se trató de un momento en el cual si bien la idea de la representación era una obra, sin duda política, dicha obra 
todavía estaba encapsulada dentro del circuito del arte. En este momento, se produjo un quiebre hacia la idea de que la obra de arte podía ser apropiada por la multitud en el contexto de un movimiento social que estaba liderando la resistencia a la Dictadura. Del mismo modo, en los pañuelazos la apuesta fue poder construir una narrativa sobre los sentidos y sobre la importancia de que las mujeres puedan decidir sobre sus cuerpos, y que circulara por los medios y las redes sociales. Como una obra política y artística para instalarse en la agenda pública y replicarse en el espacio virtual.

Las intervenciones en los pañuelazos no tuvieron ni autoras ni autores. Sus protagonistas fueron todas las mujeres que participaron; juntas, como el colectivo indisociable y heterogéneo que son. Contrariamente a las expresiones provenientes de un tipo de arte consagrado, en donde hay un/a artista que firma su gran obra maestra, en este tipo de intervenciones no hay una autoría individual sino que prima lo colectivo. Lo importante es el proceso de realización conjunta, no hay nombres, apellidos o artistas reconocidos/as a quienes adjudicar la crítica. El poder del artista consagrado no entra en juego aquí. La potencia de estas intervenciones estuvo dada, justamente, por la acumulación colaborativa y colectiva, no por la individualidad de un genio creador. La escritora Nina Felshin (2001), explica que el conjunto de prácticas pertenecientes al arte activista está expandiendo de un modo creativo las fronteras del arte y el público, y redefiniendo el papel del/de la artista. En esta línea, la investigadora feminista Sofía Menoyo (2011) destaca que el arte activista «normalmente tiene lugar en espacios públicos; toma forma de intervención temporal; emplea técnicas de los medios de comunicación dominantes y se distingue por el uso de métodos colaborativos de ejecución» (p. 6).

Coherente con los planteos disruptivos del feminismo, que cuestiona un orden patriarcal establecido, la ruptura desde la creación artística colectiva y anónima de-construye la figura del "genio creador», lo que implica un cuestionamiento al sujeto moderno de la cultura. Supone, así, una renuncia a la jerarquía que conlleva y que connota la palabra artista, en tanto sujeto que reúne ciertas condiciones que lo/a legitiman y lo/a habilitan como «el/la» productor/a de arte y cultura. En los pañuelazos, en cambio, todas las mujeres que en los diferentes lugares del mundo quisieron participar pudieron hacerlo; las convocatorias invitaban a animarse, a llevar elementos de color verde y a acercarse a compartir. Esto sugiere un posicionamiento diferente como sujetas hacedoras y promotoras de cultura. 
Propone una forma diferenciada de establecer las relaciones y los vínculos entre pares y con aquellas/os a las/os que está dirigida su producción. Relaciones y vínculos que no están determinados por órdenes jerárquicos o por relaciones de poder sino todo lo contrario: por modos de hacer conjuntos, horizontales y colectivos (Menoyo, 2011).

Esta fuerte apropiación del espacio público por parte del movimiento feminista no es casual. Que la intervención pública implique mujeres en la calle, manifestándose por un asunto supuestamente del orden de lo privado, implica poner en práctica uno de los postulados centrales del feminismo que incita a que las mujeres disputen estos espacios, históricamente ocupados por varones y diferenciados del ámbito de lo privado al que socialmente se las ha confinado, como modo de representar lo que han expresado las feministas de los años sesenta: «Lo personal es político». Así, las mujeres se pronunciaron colectivamente desde su subjetividad y en un lazo solidario, y construyeron desde la empatía un poder político que se instaló en el espacio público y puso en jaque los discursos que operan desde los sectores de poder hegemónico.

Finalmente, otro de los componentes que vincula las intervenciones de los pañuelazos con aquellas realizadas por las Madres de Plaza de Mayo se relaciona con la socialización de una demanda, con la colectivización del dolor de manera solidaria y hermanada. Longoni (2009) analiza el caso de las pancartas con los rostros de militantes desaparecidos/as que cada madre llevaba de su hijo/a. La autora explica que desde 1983 se produjo un debate al interior de la Asociación de Madres de Plaza de Mayo en torno a lo que Hebe de Bonafini ${ }^{4}$ conceptualizó como «la socialización de la maternidad», una suerte de socialización del dolor mediante la cual se diluye el vínculo que une a un/a hijo/a con una madre o con un padre. Esto genera que cualquiera pueda portar la pancarta de cualquier otro hijo o hija como modo de compartir el dolor y la lucha.

En los pañuelazos en apoyo a la ley de IVE también la solidaridad y la colectivización de la demanda fueron componentes centrales. La lucha y el poner el cuerpo por la posibilidad de que las mujeres en la Argentina puedan abortar de manera legal, segura y gratuita fue llevada a cabo por mujeres de diversos sectores, algunas con condiciones socioeconómicas que les permitirían abortar de manera no legal, pero sí segura. La demanda fue expresada en diversas manifestaciones artísticas por mujeres hermanadas en una lucha que es no solo por ellas, sino también por las que no pueden estar ahí o por las que ya no están. 


\section{Reflexiones finales}

Así, concluimos que el vínculo entre política y cultura puede ser analizado también desde un registro estético y comunicacional. La relación entre arte, espacio público y movimientos feministas, de gran vigencia en las prácticas artísticas actuales, desafía las perspectivas tradicionales de análisis de la obra de arte y requieren de reactualizar los debates sobre los modos de producción y de circulación de nuevas narrativas. Los cruces entre estética y política en la trama urbana dejan ver cómo la crítica desde la teoría feminista ha permitido desdibujar los límites de las categorías conocidas o enmarcadas dentro de la institución Arte y ha hecho frente a los cánones establecidos por el arte «puro». Como explica Bourdieu (2010):

El arte puro asume el contrato tácito por el cual las fracciones dominantes de la burguesía reconocen al intelectual y al artista el monopolio de la producción de la obra de arte concebida como instrumento de goce y como instrumento de legitimación simbólica del poder económico o político mediante el cual se aleja de las cosas serias, a saber, las cuestiones sociales y políticas (p.118).

En Latinoamérica, el ejercicio y el goce de los derechos sexuales de las mujeres y las identidades feminizadas se mantienen como una deuda de la democracia y de la sociedad. La imposición de visiones morales y religiosas, la discriminación, la violencia estructural contra los cuerpos de las mujeres y la feminización de la pobreza impiden que las mujeres puedan decidir libremente sobre sus vidas. Por eso, la lucha se desarrolla en diversos frentes y con diferentes herramientas. El arte es una de ellas y el espacio público, uno de sus escenarios.

La potencia del activismo artístico apropiado por el movimiento feminista tiene un peso central en esta lucha. Tal como señala Felshin (2001), este tipo de unión entre arte político y activismo es, en primer lugar, procesual, tanto en sus formas como en sus métodos. En segundo lugar, se caracteriza por apropiarse de la trama urbana como espacio de realización, dinámica que resulta muy diferente a la establecida por los clásicos ámbitos de exhibición consagrados del mundo del arte. En tercer lugar, como práctica se relaciona muchas veces con intervenciones 
temporales, con modos de estar en el espacio de los cuerpos. Y una cuarta característica es que gran parte de estas prácticas artísticas emplea técnicas diversas, híbridas, porosas. Métodos que se inspiran, frecuentemente, fuera del mundo del arte, lo que constituye un modo de asegurar la participación del público o de la comunidad.

Para aportar otras aristas al análisis de la protesta social, resulta necesario, pues, vislumbrar cómo existe un campo de cruces posibles e imperiosos entre la política, el arte y la cultura en tanto componentes que promueven y que habilitan transformaciones sociales. Cruces que tejen, así, un entramado posible, necesario y urgente desde el cual las mujeres del movimiento feminista argentino puedan avanzar en el proceso de lucha por la-ojalá pronta-aprobación de la ley.

\section{Referencias}

Bilbao, B. (2017). «Ni una menos» y "paro nacional de mujeres»:

reflexiones a la configuración de acontecimiento cultural e intervención artística por parte de las mujeres en el espacio público. Trabajo presentado en el $X$ Seminario Internacional Políticas de la Memoria, realizado en el Centro cultural Haroldo Conti. Recuperado de http://conti.derhuman.ju.g.gov.ar/2018/01/seminario/mesa_13/bilba o_mesa_13.pdf

Bourdieu, P. (2010). El sentido social del gusto. Elementos para una sociología de la cultura. Ciudad Autónoma de Buenos Aires, Argentina: Siglo XXI.

Butler, J. (2019). Activismo y pensamiento [Exposición]. Universidad Nacional de Tres de Febrero, Argentina. Recuperado de https://www.youtube.com/watch?v=YSZrXUUDLpQ 
CEPAL (2013). Estudio Económico de América Latina y el Caribe 2013: tres décadas de crecimiento económico desigual e inestable. Recuperado de https://www.cepal.org/es/publicaciones/1085-estudio-economicoamerica-latina-caribe-2013-tres-decadas-crecimiento-economico

Elizalde, S. (2018). Hijas, hermanas, nietas: genealogías políticas en el activismo de género de las jóvenes. Ensambles, 4(8), 86-93. Recuperado de http://www.revistaensambles.com.ar/ojs-

\subsection{1/index.php/ensambles/article/view/149}

Felshin, N. (2001). «¿Pero esto es arte? El espíritu del arte como activismo». En P. Blanco y otros, Modos de hacer. Arte crítico, esfera pública y acción directa (pp. 73-94).

Salamanca, España: Editorial de la Universidad de Salamanca.

De Titto, J. (2018). «Crear un nuevo mundo también es narrarlo». En AA.VV., La cuarta ola feminista (pp. 55-65). Ciudad Autónoma de Buenos Aires, Argentina: Oleada Digital / Mala Junta. Recuperado de https://malajunta.org/wpcontent/uploads/2019/06/libro-mala-junta-web-final-2.pdf

García Canclini, N. y Cruces, F. (2012). Jóvenes, culturas urbanas y redes digitales. Barcelona, España: Ariel.

Laddaga, R. (2006). Estética de la emergencia. La formación de otra cultura de las artes. Ciudad Autónoma de Buenos Aires, Argentina: Adriana Hidalgo.

Longoni, A. (2010a). Activismo artístico en la última década en Argentina. Algunas acciones en torno a la segunda desaparición de Jorge Julio López. Errata, (1), 16-35. 
Longoni, A. (2010b). Arte y Política. Políticas visuales del movimiento de derechos humanos desde la última dictadura: fotos, siluetas y escraches. Aletheia, 1(1). Recuperado de http://sedici.unlp.edu.ar/handle/10915/69047

Mayer, M. (2007). «De la vida y el arte como feminista».

En K. Cordero e I. Sáenz (Coords.), Critica feminista en la teoría e historia del arte (pp. 401-413). Ciudad de México, México: Universidad Iberoamericana.

Menoyo, S. (septiembre de 2011). Intervenciones públicas performativas. Aportes de la experiencia feminista al mundo del arte. Trabajo presentado en las II Jornadas del Centro Interdisciplinario de Investigaciones en Género de la Facultad de Humanidades y Ciencias de la Educación de la Universidad Nacional de La Plata. Recuperado de http://www.memoria.fahce.unlp.edu.ar/trab_eventos/ev.4929/ev.4 929.pdf

Schuster, F. (2005). «Las protestas sociales y el estudio de la acción colectiva». En F. Schuster, F. Naishtat, G. Nardacchione y S. Pereyra (Comps.), Tomar la palabra: estudios sobre protesta social y acción colectiva en la Argentina contemporánea (pp. 43-84). Ciudad Autónoma de Buenos Aires, Argentina: Prometeo.

\section{Notas}

1 Expediente 230-D-2018.

2 En América Latina, la tasa de uso de Internet de las mujeres es en promedio 8,5 \% menor que la de los hombres según datos de la Comisión Económica para América Latina y el Caribe (CEPAL, 2013).

3 Glitter: polvo muy fino, brillante y de colores, que se utiliza para adornar o para decorar.

4 Hebe de Bonafini es cofundadora de la Asociación Madres de Plaza de Mayo, organización de madres de detenidos/as desaparecidos/as durante la última Dictadura cívico eclesiástico militar argentina y de la Fundación Madres de Plaza de Mayo. 